\title{
Coseeded Schwann cells myelinate neurites from differentiated neural stem cells in neurotrophin-3-loaded PLGA carriers
}

This article was published in the following Dove Press journal:

International Journal of Nanomedicine

13 April 2012

Number of times this article has been viewed

\author{
Yi Xiong ${ }^{1, *}$ \\ Ji-Xiang Zhu ${ }^{2, *}$ \\ Zheng-Yu Fang' \\ Cheng-Guang Zeng ${ }^{2}$ \\ Chao Zhang' \\ Guo-Long $\mathrm{Qi}^{3}$ \\ Man-Hui Li' \\ Wei Zhang' \\ Da-Ping Quan ${ }^{2}$ \\ Jun Wan ${ }^{1,4}$
}

'Biomedical Research Institute, ShenzhenPKU-HKUST Medical Center, Shenzhen, ${ }^{2}$ DSAPM Lab, PCFM Lab, Institute of Polymer Science, School of Chemistry and Chemical Engineering, Sun Yat-sen University, Guangzhou, ${ }^{3}$ Department of Medical Information, Medical Collage of Jinan University, Guangzhou, ${ }^{4}$ Division of Life Science, the Hong Kong University of Science and Technology, Clear Water Bay, Kowloon, Hong Kong, People's Republic of China

*These authors contributed equally to this manuscript

Correspondence: Da-Ping Quan Institute of Polymer Science, School of Chemistry and Chemical Engineering, Sun Yat-sen University, West Xingang Road, Guangzhou, 510275, People's Republic of China

Tel +86 02084 I $\quad$ 4030

Fax +86 02084 I I 2245

Email cesqdp@mail.sysu.edu.cn

Jun Wan

Biomedical Research Institute, Shenzhen-PKU-HKUST Medical Center,

I I 20 Lianhua Road, Shenzhen, 5I8036,

People's Republic of China

Tel +86755830 67072

Fax +86 75583913095

Email wanj@ust.hk

\begin{abstract}
Biomaterials and neurotrophic factors represent promising guidance for neural repair. In this study, we combined poly-(lactic acid-co-glycolic acid) (PLGA) conduits and neurotrophin-3 (NT-3) to generate NT-3-loaded PLGA carriers in vitro. Bioactive NT-3 was released stably and constantly from PLGA conduits for up to 4 weeks. Neural stem cells (NSCs) and Schwann cells (SCs) were coseeded into an NT-releasing scaffold system and cultured for 14 days. Immunoreactivity against Map2 showed that most of the grafted cells $(>80 \%)$ were differentiated toward neurons. Double-immunostaining for synaptogenesis and myelination revealed the formation of synaptic structures and myelin sheaths in the coculture, which was also observed under electron microscope. Furthermore, under depolarizing conditions, these synapses were excitable and capable of releasing synaptic vesicles labeled with FM1-43 or FM4-64. Taken together, coseeding NSCs and SCs into NT-3-loaded PLGA carriers increased the differentiation of NSCs into neurons, developed synaptic connections, exhibited synaptic activities, and myelination of neurites by the accompanying SCs. These results provide an experimental basis that supports transplantation of functional neural construction in spinal cord injury.
\end{abstract}

Keywords: PLGA, NT-3, neural stem cells, Schwann cells, myelin sheath

\section{Introduction}

Spinal cord injury (SCI) is a common medical problem, which can result in axonal demyelination, loss of both sensory and motor neuron function, and even neuronal damage and death. ${ }^{1}$ SCI triggers a cascade of events, including infiltration macrophages, activation of resident glial cells, and formation of cavities in the injury site. ${ }^{2}$ The pathological process of SCI is complicated and involves multiple factors from different cell types, which results in a lack of effective treatment of the disease. Initial experimental approaches, which aimed to restore neuronal circuits in SCIs, focused on the use of cultured neurons and supporting cells to replace damaged areas of the tissue. ${ }^{3}$

Schwann cells (SCs), the myelin-forming cells of the peripheral nervous system, play a crucial role in nerve regeneration through production of neurotrophic growth factors and excretion of extracellular matrices. ${ }^{4,5}$ These features are suggestive of $\mathrm{SCs}$ ' therapeutic potential for spinal cord repair., ${ }^{3,6-8}$ It has been demonstrated that an SC-loaded scaffold can promote limited axonal regeneration, and modestly improve hind limb motor function. ${ }^{6,8}$ Nevertheless, keeping grafted SCs alive within the SCI site remains a challenge. ${ }^{6}$

Stem cell-based therapy for SCI has also attracted much attention since the discovery of neural stem cells (NSCs) in mammals. ${ }^{9,10}$ Implantation of cultured 
NSCs was shown to enhance neuroprotection, stimulate neuroplasticity, and rescue neuronal loss in an experimental SCI model. ${ }^{11-13}$ However, effectiveness of NSC transplantation in CNS trauma remains limited for two reasons: firstly, grafted NSCs rarely differentiate into mature neurons in spinal cord lesions, ${ }^{14,15}$ and secondly, NSCs survive poorly when transplanted, which attenuates their effect on the restoration of neural circuits. ${ }^{16,17}$ Therefore, in order to adequately evaluate the therapeutic potential of NSCs in bridging a lesion gap in SCI, it is necessary to investigate regimens that further augment the survival and differentiation of transplanted NSCs.

Neurotrophins (NTs) play important roles in neuronal survival, differentiation, and neurite outgrowth. ${ }^{18} \mathrm{NSCs}$ transfected with NT-3, ${ }^{19}$ or seeded into the NT-3-chitosan carriers, ${ }^{13,20}$ yield a high percentage of differentiation toward neurons. Here, we engineered an NT-3-loaded poly-(lactic acid-co-glycolic acid) (PLGA) carrier, and tested whether coseeding NSCs and SCs into an NT-releasing scaffold system would permit grafted cells to survive, differentiate into neurons, myelinate, and then form a functional construct. Any such functional neural construction may be particularly useful as engineered nerve tissue replacement for SCI.

\section{Materials and methods Preparation of PLGA scaffold}

A macroporous PLGA scaffold was synthesized with a 75:25 monomer ratio (D,L-lactide: glycolide) by ringopening polymerization using $\mathrm{Sn}(\mathrm{Oct})_{2}$ as a catalyzer, and dodecanol as an initiator. The average molecular weight of the PLGA copolymer was $1.22 \times 10^{5}$ (Mn GPC). To obtain different pore sizes, polymer concentration was employed from $2.5 \%$ to $20 \%$. Sodium chloride as a porogen was added into the polymer solution with $\mathrm{PLGA} / \mathrm{NaCl}$ in a weight ratio of 1:9. The PLGA scaffold formed pores of varying sizes, ranging from a few $\mu \mathrm{m}$ up to $200 \mu \mathrm{m}$ that were suitable for seeding neurospheres with diameters of $100 \mu \mathrm{m}$ to $300 \mu \mathrm{m}$. PLGA rods with longitudinal parallel-channels were fabricated by an injection molding, combined with thermally-induced phase separation. The lumens of the mold were pretreated with chlorotrimethylsilane, and were placed into the freezer at $-40^{\circ} \mathrm{C}$ for at least 1 hour. A $5 \%(\mathrm{w} / \mathrm{v})$ PLGA solution in 1,4-dioxane was rapidly injected into the cold mold with a syringe. Injection pressure at the port of the syringe was maintained by keeping it completely frozen until its introduction into the polymer solution. The mold was then placed in the freezer at $-40^{\circ} \mathrm{C}$ for another 2 hours. The scaffold was then lyophilized under $0.940 \mathrm{mbar}$ at $0^{\circ} \mathrm{C}$ for at least 4 days. The polymer scaffold was then trimmed into a rod shape $2 \mathrm{~cm}$ in length and $5 \mathrm{~mm}$ in diameter.

\section{NSCs preparation and identification}

Whole hippocampi aged 3-5 days from Sprague-Dawley (SD) rat pups were dissected and dissociated in Hanks' balanced salt solution (HBSS). After centrifuging at $1000 \mathrm{rpm}$ for 5 minutes, the supernatant was removed. The pellet was resuspended in $5 \mathrm{~mL}$ basal medium including: Dulbecco's modified Eagle's medium (DMEM)/F12 at a ratio of 1:1, containing B27 supplement $20 \mu \mathrm{L} / \mathrm{mL}$ (Gibco, Carlsbad, CA) and basic fibroblast growth factor $20 \mathrm{ng} / \mathrm{mL}$ (Invitrogen, Carlsbad, CA). Cells were then plated onto 75-mL culture flasks, with fresh medium every 3 days. Cultured cells typically grew as suspending neurospheres and were passaged once per week.

\section{SCs culture and purification}

Cultured SCs were obtained from 3-day-old SD rats as described above. ${ }^{12}$ Sciatic nerves were harvested with $0.25 \%$ trypsin for 15 minutes at $37^{\circ} \mathrm{C}$ followed by $0.16 \%$ collagenase (both trypsin and collagen; Sigma-Aldrich, $\mathrm{St}$ Louis, MO) for 20 minutes. Following harvest, cells were centrifuged at $1000 \mathrm{rpm}$ for 5 minutes, resuspended in DMEM/F 12 with 10\% fetal bovine serum (FBS) (Invitrogen) and plated on poly-L-lysine $0.01 \%$ (Sigma-Aldrich)-coated plates at $1 \times 10^{5}$ cells $/ \mathrm{mL}$. The following day, these cells were treated with cytosine arabinoside $\left(1 \times 10^{-5} \mathrm{M}\right.$; SigmaAldrich) for $24-48$ hours to rapidly remove fibroblasts. Cells were fed every 3-4 days and passaged every week. The purity of cultured SCs was determined by immunostaining, using an antibody against the SC marker S-100, with DAPI (4',6-diamidino-2-phenylindole; Invitrogen) as a counter stain. Purity of the SC cultures used for implantation in this study was at least $90 \%$.

\section{Preparation of NT-3-loaded PLGA carriers}

Silk fibroin (SF), a fibrous protein biopolymer derived from the silkworm Bombyx mori, is widely used in protein-delivery systems. ${ }^{25,26} \mathrm{SF}$ was prepared as described. ${ }^{25}$ Briefly, cocoons from B. mori were boiled in ultrapurified water (UPW) containing $0.02 \mathrm{M} \mathrm{Na}_{2} \mathrm{CO}_{3}$, rinsed thoroughly with distilled water to extract the glue-like sericin proteins and wax, and then dissolved in $9 \mathrm{M} \mathrm{LiBr}$ at $55^{\circ} \mathrm{C}$ to obtain a $10 \%$ aqueous $\mathrm{SF}(\mathrm{w} / \mathrm{v})$ solution. Then, $10 \%$ aqueous SF solution was dialyzed with UPW and diluted into $1 \%, 3 \%$, or $6 \%$ SF solution. Recombinant human NT-3 (PeproTech, Rocky Hill, NJ) was embedded by 
adding $10 \mathrm{mg}$ NT-3 to $1 \mathrm{~mL}$ SF solution $(1 \%, 3 \%$, or $6 \%$, respectively). NT-3-SF solution was subsequently sterilized by $0.25 \mu \mathrm{m}$ filter (Invitrogen). PLGA rods were cut into $2 \mathrm{~mm}$ slices, sterilized in $70 \%$ alcohol for 10 minutes, rinsed with sterile phosphate-buffered solution (PBS; $\mathrm{pH}$ 7.4) for 30 minutes, soaked in NT-3-SF solution, stirred at $0^{\circ} \mathrm{C}$ for 6 hours, air-dried under laminar airflow overnight, and subsequently treated with $70 \%$ alcohol for 5 minutes to render them insoluble by SF physical induction of $\beta$-sheet formation. The NT-3-loaded PLGA carriers were then stored in a dessicator and rinsed with sterile PBS for 30 minutes before use.

\section{Kinetics of NT-3 release from NT-3-loaded PLGA carriers}

Five independent samples of medium supernatants from PLGA carriers with different SF concentrations were collected at $1,3,6,12$, and 24 hours, between 1 and 5 weeks after the initiation of the coculture. Enzyme-linked immunosorbent assay (ELISA) (Becton Dickinson, Franklin Lakes, NJ) was performed according to the manufacturer's instructions, in order to determine the kinetics of NT-3 released from NT-3loaded PLGA carriers. Absorbance was measured at $450 \mathrm{~nm}$ using a plate reader (Model 680; Bio-RAD, Hercules, CA), and NT-3 concentration was determined by comparing the reading to the standard curve.

\section{NSCs and SCs seeding in PLGA scaffolds}

NSCs from neurospheres were dissociated mechanically and mixed with SCs after counting cells on a hemocytometer. Cells were then suspended in basic medium (DMEM/F12 with $10 \% \mathrm{FBS}$ ), and seeded under three separate conditions: PLGA only, PLGA-SF (3\% SF solution), and PLGA-SFNT-3 (3\% SF solution with NT-3). In order to seed neurospheres into the scaffold, we put $3.1 \times 10^{6}$ cells in $20 \mathrm{~mL}$ culture medium consisting of DMEM/F12 at a ratio of $1: 1$, $10 \% \mathrm{FBS}$, and $50 \mu \mathrm{g} / \mathrm{mL}$ ascorbic acid (Sigma-Aldrich) on top of PLGA slice with Waterman filter paper (\#1) beneath the slice to gently suck cells into the pores. Slices were incubated in $35 \mathrm{~mm}$ culture dishes for 14 days, with the culture medium replaced every 2 days.

\section{Live-dead staining}

After 14 days of culture, PLGA slices were rinsed with $0.1 \mathrm{M}$ PBS ( $\mathrm{pH} \mathrm{7.4)} \mathrm{for} 30$ minutes, followed by staining in $2 \mathrm{~mL}$ $0.1 \mathrm{M}$ PBS containing $2 \mathrm{mM}$ of calcein-AM and $4 \mathrm{mM}$ ethidium homodimer (EthD-III) (Live/Dead Assay Kit; Invitrogen) for 1 hour at $37^{\circ} \mathrm{C}$. Slices were then fixed with $4 \%$ formaldehyde and cryosectioned into $20 \mu \mathrm{m}$ continuous sections.
Five sections from the peripheral edge of the PLGA slices (peripheral sections) and five sections from the center of the slices (center sections) were used for comparison. Live cells stained with calcein-AM showed a green color, and dead cells stained with EthD-III showed a red color under fluorescent microscopy. Cell death rate was calculated by determining the percentage of EthD-1-positive cells over the total number of cells from five randomly selected fields in each section.

\section{Immunocytochemistry}

Differentiation and synaptogenesis were determined using immunocytochemistry (ICC) staining of cryosections, following standard protocol. Antibodies used in this section included rabbit anti- $\gamma$-aminobutyric acid and rabbit antiglutamate, both at ratios of 1:300, mouse anti-Map2, rabbit anti-TuJ-1, rabbit anti-5-HT, and rabbit anti-MBP, all at ratios of 1:500, and also rabbit anti-glial fibrillary acidic protein and mouse anti- $\mathrm{O}_{4}$, again, both at ratios of 1:1000 (all from Sigma-Aldrich), as well as mouse anti-PSD95 and rabbit anti-synapsin, both at ratios of 1:500 (both from Cell Signaling Technologies, Beverly, MA), and finally rabbit anti-ChAT and rabbit anti-S100, both at a ratio of 1:500 (both from Chemicon International, Inc, Billerica, MA).

\section{Western blotting}

PLGA slices for cell coculture were triturated using a firepolished glass pipette with $0.25 \%$ trypsin in $0.03 \%$ EDTA, which was then rinsed three times. Cells were collected and lysed in RIPA buffer $(1 \times$ PBS, $1 \%$ NP40, $0.5 \%$ sodium deoxycholate, $0.1 \%$ sodium dodecyl sulfate [SDS], plus the protease inhibitor, phenylmethylsulfonyl fluoride). The protein concentration in cell lysates was determined by a BCA protein assay kit (Pierce Protein Research Products; Thermo Fisher Scientific Inc, Rockford, IL). Whole cell lysates were separated by $10 \%$ SDS-polyacrylamide gel, followed by the standard Western blotting protocol using antibodies against TuJ-1 and anti-GFAP. Lysates from neonatal rat brains were used as a positive control. Signal intensity of the blots was measured using TotalLab software (Nonlinear USA Inc, Durham, NC). All experiments were repeated three times, and the statistics were analyzed using SPSS software (version 11.5; SPSS, Chicago, IL).

\section{Ultrastructural observation}

PLGA scaffolds were fixed in 2\% glutaraldehyde for 90 minutes, osmicated with $1 \%$ osmic acid for 1 hour, and then dehydrated with a gradient concentration of ethanol. Samples were coated with platinum and examined under the 
scanning electron microscope (SEM; Philips XL30 FEG; Philips, Eindhoven, The Netherlands) at $10 \mathrm{kV}$.

In preparation for viewing under transmission electron microscope (TEM; Philips CM 10; Philips), the PLGA-SFNT-3 scaffold was fixed with $2.5 \%$ glutaraldehyde at $4{ }^{\circ} \mathrm{C}$ for 30 minutes, followed by osmication and dehydration. The scaffolds were then embedded in epon overnight, followed by polymerization at $60^{\circ} \mathrm{C}$ for 48 hours. Use of acetone or epoxypropane was avoided, since PLGA is destroyed by these organic solvents. Ultrathin sections were obtained using the Reichert-Jung Ultracut E ultramicrotome (C. Reichert AG, Vienna, Austria) and examined under TEM.

\section{Detection of synaptic activity}

Grafted cells were cultured for 14 days in different PLGA scaffolds. Cells were then loaded with $10 \mu \mathrm{M}$ FM1-43 [(N-3-triethylammonmpropyl)-4-(4-(dibutylamino)styryl)] or $10 \mu \mathrm{M}$ FM4-64 [N-(3-triethylammoniumpropyl)-4-(6(4-(diethylamino)phenyl) hexatrienyl)pyridiniumdibromide] (both from Invitrogen) under high $\mathrm{K}^{+}(50 \mathrm{mM})$ concentration for 10 minutes. ${ }^{21,22}$ High $\mathrm{K}^{+}$levels stimulated recycling of endocytic synaptic vesicles containing FM1-43 or FM4-64. Scaffolds were then rinsed three times (for 15-20 minutes each time) in medium without FM1-43 or FM4-64, to bring endocytic/exocytotic activities to base level. This also eliminated nonspecific labeling of cytoplasmic membranes, but kept synaptic vesicles labeled by FM1-43 or FM4-64. Cells were then unloaded by induction of depolarization with high $\mathrm{K}^{+}$for the second time. Release of FM1-43-or FM4-64-labeled synaptic vesicles was imaged under fluorescent microscopy, using a Zeiss LSM 710 laser scanning microscope (Carl Zeiss Shanghai Co, Ltd, Beijing, China).

\section{Analysis of MBP-positive fiber}

Myelin basic protein (MBP), a marker of myelin sheaths, is important in the process of myelination. MBP-positive fibers were examined by single or costaining of PLGA sections with Map2 and MBP and visualized under fluorescent microscopy. For each experimental group, at least five fields of each section (including four corners and one center) were imaged. MBP signal spinning longer than $10 \mu \mathrm{m}$ was considered as indication of the presence of MBP fibers. The percentage of positive fibers of each group was determined relative to the sum of positive ones. All experiments were repeated three times.

\section{Statistical analysis}

For quantification of cell types in any given experiment, at least five random fields were selected and photographed under
$20 \times$ lens. The percentage of positive cells was determined relative to the total number of DAPI-labeled cell nuclei. We counted about 500 cells in every group. Statistical analyses were performed using ANOVA for Student's $t$-test. A $P$-value smaller than 0.05 was considered statistically significant.

\section{Results \\ Culture of NSCs and SCs}

NSCs and SCs were isolated from the whole hippocampi and sciatic nerves of rat pups. Cells were observed under phasecontrast microscope 14 days later. SCs displayed characteristic morphology, with spindle-shaped bodies and bipolar processes (arrow in Figure 1A). To determine the purity of cultured SCs, cells were immunostained with antibody against S100, a marker for SC. Approximately $95 \%$ of the cells were S100-positive (Figure 1B). NSCs were assessed with nestin, a marker for neural precursors. Immunostaining results demonstrated that almost two-thirds of cultured cells were nestin-positive (Figure 1C, data not shown),
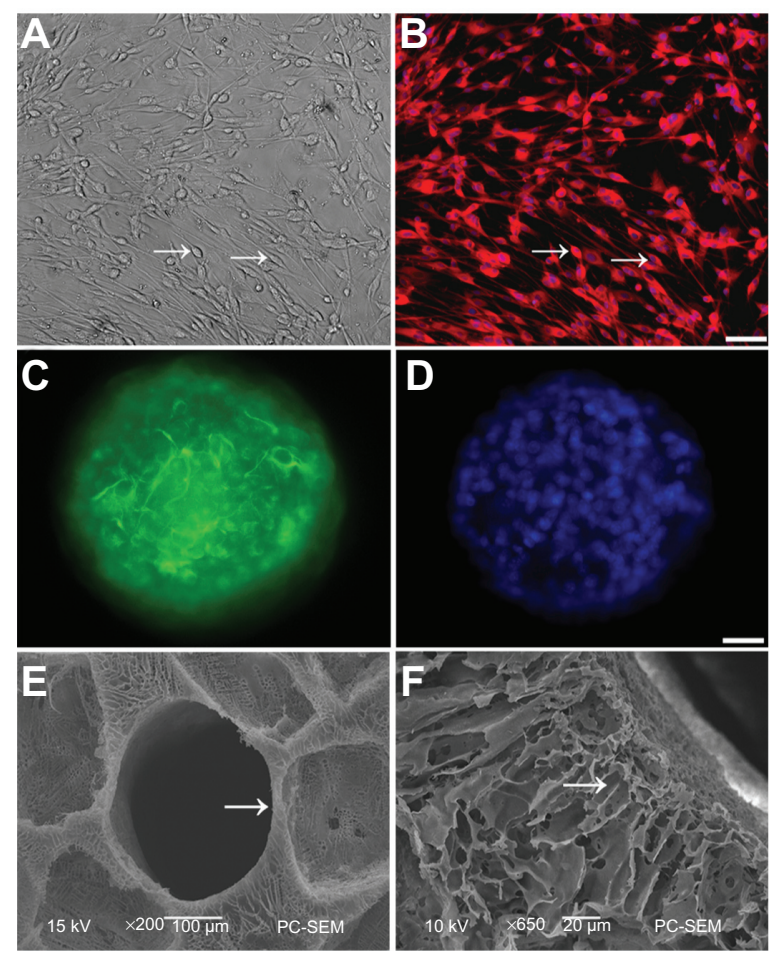

Figure I Schwann cells (SCs) and neural stem cells (NSCs) culture and identification. (A) SCs (arrow) were viewed under light microscopy; (B) Cell bodies (arrow) were stained with antibodies against $\mathrm{SI} 00$ and nuclei were labeled by DAPI; (C) Neurospheres were stained with antibodies against nestin, a marker of NSCs; (D) Nuclei in the neurosphere were labeled by DAPI. Scale bar $=20 \mu \mathrm{m}$ in (A-B) and $10 \mu \mathrm{m}$ in (C-D); (E) SEM of a transverse section of PLGA scaffold shows one of the tubes (arrow). There are numerous pores with variable diameters between tubes; (F) A longitudinal section of PLGA was imaged under high SEM.

Note: The arrow points to the radial channel that extends from the scaffold tube. Abbreviations: DAPI, 4',6-diamidino-2-phenylindole; SEM, scanning electron microscope; PLGA, poly-(lactic acid-co-glycolic acid). 
and the nuclei were labeled by DAPI (Figure 1D). These NSCs and SCs were then grafted into the NT-3-loaded PLGA carriers.

\section{The structure of PLGA scaffolds}

To determine whether our PLGA scaffolds were able to form an optimal structural environment for the seeded NSCs, we examined the architecture of the scaffolds under SEM. The PLGA rods had an average length of $2 \mathrm{~mm}$, and an average diameter of $5 \mathrm{~mm}$. Tubes in each rod were $0.5 \mathrm{~mm}$ in diameter (arrow in Figure 1E). Numerous pores with diameters from $200 \mu \mathrm{m}$ to $300 \mu \mathrm{m}$ were dispersed in the PLGA scaffold. High magnification SEM of a longitudinal PLGA section showed many channels (arrow in Figure 1F) radially extended from the tube, with many small pores distributed in their walls.

\section{Bioactivity of NT-3 released from PLGA carriers}

To determine whether bioactive NT-3 can be released from PLGA scaffolds, we monitored levels of NT-3 in the medium after 1 hour to 4 weeks of culture by ELISA in each of the three different groups. In the PLGA-3\% SF solution group, NT-3 release from NT-3-loaded PLGA carriers was triphasic, consisting of a typical burst of release within the
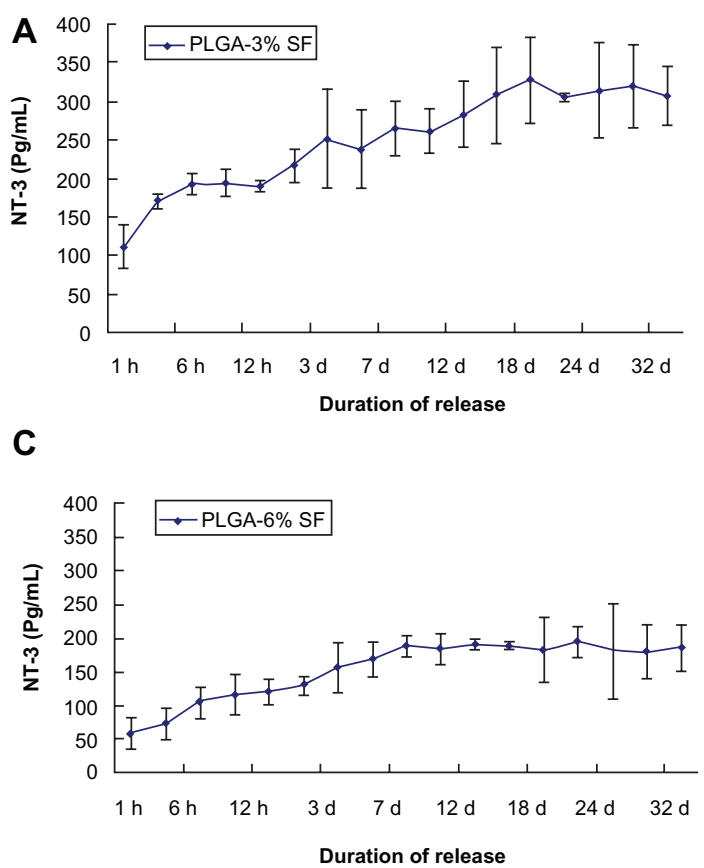

first 6 hours, followed by a period of slow increase until day 18 , and finally a stable rate until day 35 (Figure 2A). On the other hand, in the PLGA-1\% SF solution group, the release rate of NT-3 reached a peak on day 7, and thereafter began to decline (Figure 2B). In the PLGA-6\% SF solution group, the release curve of NT-3 was similar to that of the PLGA-3\% SF solution group, except for a lower level of NT-3 (Figure 2C). By day 35, the cumulative release of NT-3 was obviously highest in the PLGA-3\% SF solution group. There was no significant difference between the PLGA-1\% and $-6 \%$ SF solution groups in the total of NT-3 released (Figure 2D). Taken together, these results suggest that NT-3-loaded PLGA carriers are an efficient way of releasing bioactive NT-3, and embedding NT-3 in the PLGA-3\% SF solution not only permitted the release of more NT-3, it also ensured a stable and constant supply of NT-3.

\section{Survival and differentiation of NSCs in NT-3-loaded PLGA carriers}

To detect whether NSCs and SCs were viable in NT-3loaded PLGA carriers, cells grafted into the carriers were cultured for 14 days, and stained with calcein-AM and EthD-III. Viable cells exhibited green fluorescence (see stars in Figure 3A-C), which was generated by esterase hydrolysis of membrane-permeable, calcein-AM. Dead
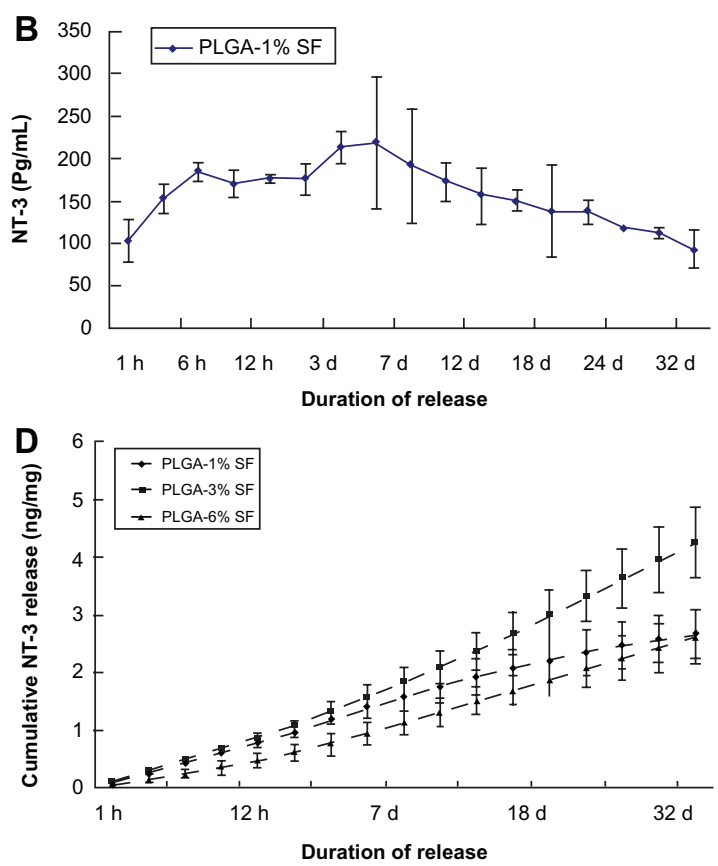

Figure 2 Secretion of NT-3 from NT-3-PLGA carriers loaded with three different SF solutions groups for at least 4 weeks. Daily release of NT-3 was examined by ELISA in (A) the 3\% SF solution group; (B) the I\% SF solution group; (C) the 6\% SF solution group, respectively; and (D) There was cumulative release of NT-3 across the three different groups after at least 4 weeks.

Note: Error bars represent mean \pm SD ( $n=3$ for each group).

Abbreviations: NT-3, neurotrophin-3; PLGA, poly-(lactic acid-co-glycolic acid); SF, silk fibroin; ELISA, enzyme-linked immunosorbent assay. 

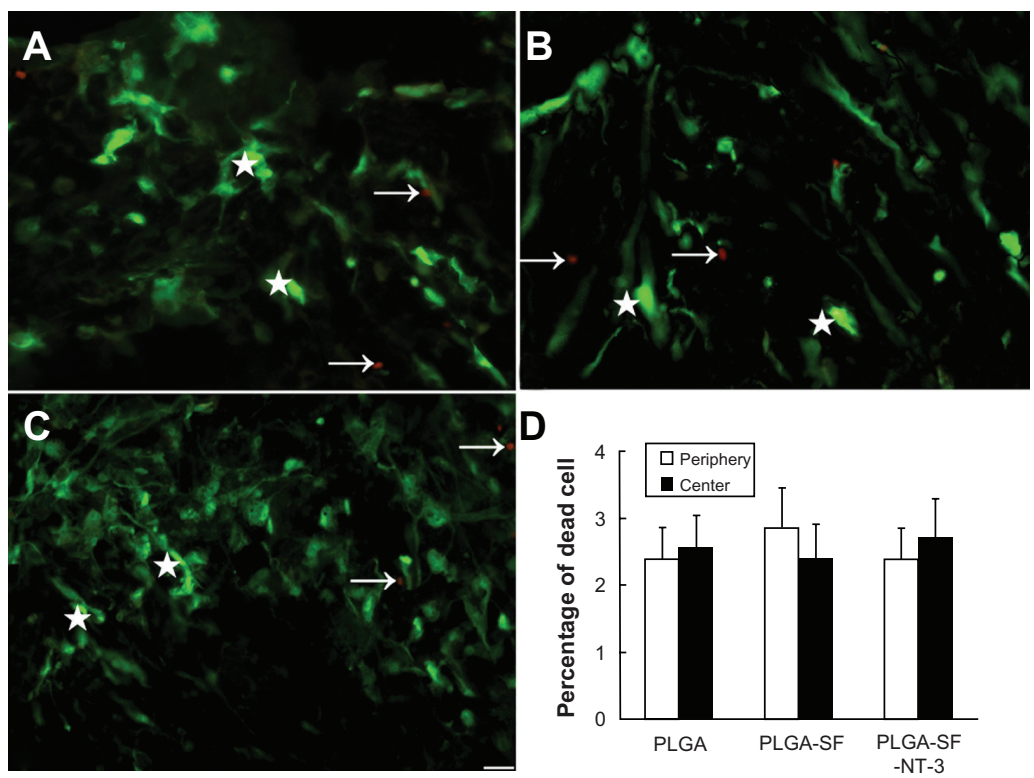

Figure 3 Survival of cultured cells in the scaffold. NSCs and SCs were cultured in the NT-3-PLGA carriers for I4 days, and stained with calcein-AM and EthD-I. Viable cells were labeled green and dead cells were marked by red fluorescence. The arrows point to dead cells in (A) PLGA only; (B) PLGA-SF; and (C) the PLGA-SF-NT-3 group. The stars mark living cells; (D) Percentage of dead cells in the periphery and center of PLGA slices.

Note: Scale bar $=20 \mu \mathrm{m}$ in A-C.

Abbreviations: NSCs, neural stem cells; SCs, Schwann cells; EthD, ethidium homodimer; NT-3, neurotrophin-3; PLGA, poly-(lactic acid-co-glycolic acid); SF, silk fibroin.

cells were marked by red fluorescence (see arrows in Figure 3A-C) from a membrane-impermeable EthD-III. Percentages of dead cells were not significantly different between either the peripheral or central sections of the scaffolds in the PLGA-only group $(2.37 \% \pm 0.63 \%$ periphery; $2.54 \% \pm 0.68 \%$ center), the PLGA-SF group $(2.91 \% \pm 0.72 \% ; 2.41 \% \pm 0.65 \%)$ and the PLGA-SFNT-3 group $(2.36 \% \pm 0.61 \% ; 2.75 \% \pm 0.74 \% ; P>0.05)$ (Figure 3D). These findings suggest that the survival of grafted cells is unaffected by their location or the nature of any extracellular matrix like SF.

To determine the differentiation of seeded NSCs in the NT-3-loaded PLGA carriers, we stained cells with differentiation markers, and found that the NSCs differentiated into all three major CNS cell types: neurons (see arrow in Figure 4A-C; green), astrocytes (Figure 4A-C and the stars in Supplementary Figure S1 A-C; red), and oligodendrocytes (see arrow in Supplementary Figure S1A-C; green). At day $14,15.28 \%$ of 587 counted cells were Map2-positive in the PLGA-only group (Figure 4A, and Table 1), as were $21.37 \%$ of 603 in the PLGA-SF group (Figure 4B), and $81.15 \%$ of 623 in the PLGA-SFNT-3 group (Figure 4C and D). The percentage of GFAPpositive cells was the lowest in the PLGA-SF-NT-3 group, compared with others (Figure 4D). Protein levels of Map2 or GFAP were determined using Western blotting. As shown in Figure 4E-H, expression of TuJ-1, the marker of neurons, was significantly higher in the PLGA-SF-
NT-3 group $(P<0.05$; Figure $4 \mathrm{E}$ and $\mathrm{F})$, but the level of GFAP was lower than in the other groups $(P<0.05$; Figure $4 \mathrm{G}$ and $\mathrm{H}$ ).

Taken together, the microenvironment in our scaffolds not only permitted grafted cells to survive, but also improved neuronal differentiation when NSCs and SCs were coseeded into NT-3-loaded PLGA carriers.

\section{Synaptogenesis of NSCs}

Double-immunostaining for synapsin-I and postsynaptic density-95 (PSD95) markers for pre- and postsynapse was used to determine whether NSCs and SCs in the NT-3-loaded PLGA carriers had developed synapses. PSD95 was mainly detected in the cell bodies, and synapsin-I was expressed in both perikaryon and neurites. As shown in Figure 5, there were three patterns of PSD95 (arrow) and synapsin-I (star) distribution: (1) cells positive for either PSD95 or synapsin (Figure 5A-C); (2) cells positive for both PSD95 and synapsin-I (Figure 5C); (3) cells with positive PSD95staining in the body, but receiving synapsin-positive neurites, or extending neurites with positive synapsin (Figure 5C). In the PLGA-SF-NT-3 group, the percentage of PSD95- or synapsin-positive cells ( $21.45 \%$ and $28.31 \%$, respectively) was significantly higher compared to other groups $(P<0.05$; Figure 5D). Interestingly, there were more cells positive for synapsin-I than cells expressing PSD95. These results indicate that neurons are able to form synapses in PLGASF-NT-3 scaffolds. 

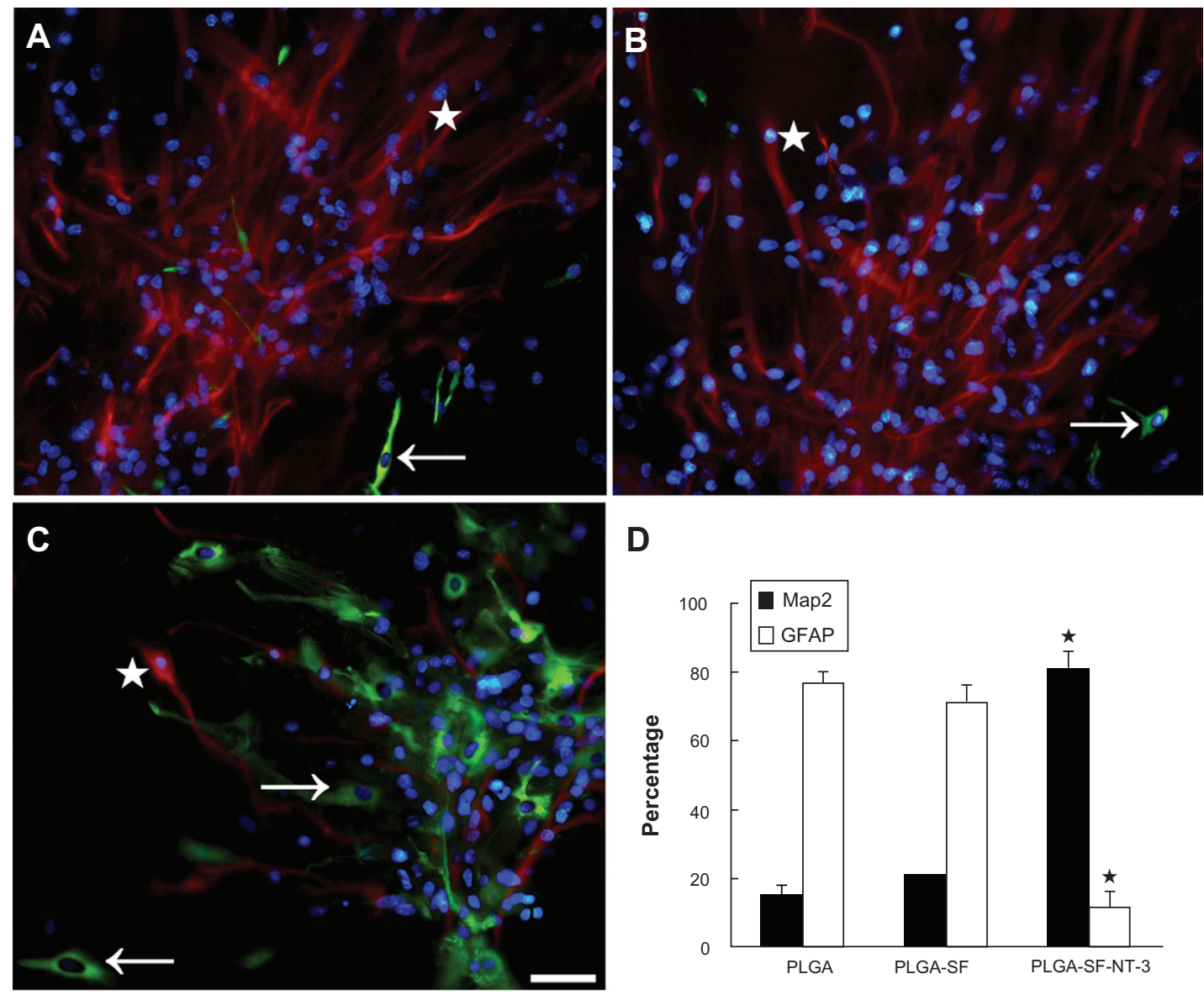

\section{E}

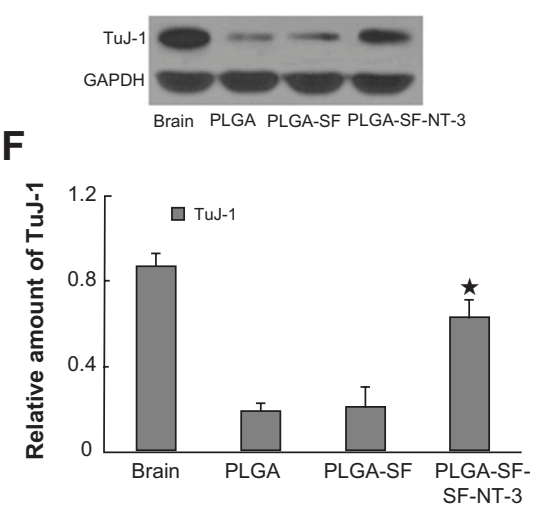

G

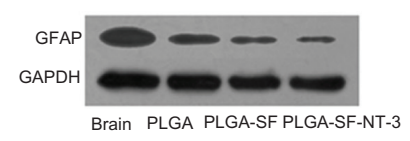

H

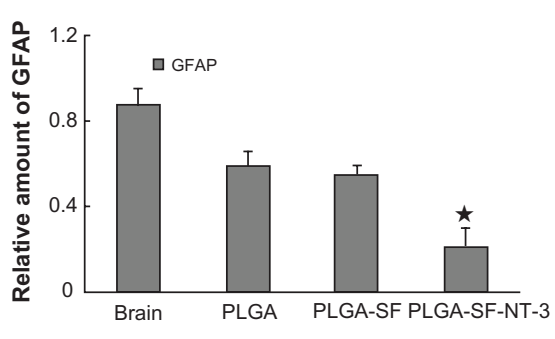

Figure 4 Differentiation detection of grafted NSCs. Cells were immunostained with markers for neurons in PLGA only. (A) PLGA-SF; (B) PLGA-SF-NT-3; (C) group (Map2; arrows in (A-C) green), astrocytes (GFAP; stars in $\mathbf{A}-\mathbf{C}=$ red). The nuclei were labeled by DAPI (=blue); (D) Compared with other groups, cells expressing Map2 in the PLGA-SF-NT-3 group were significantly higher than any other groups $(P<0.05 ; n=3$ for each group). Cells positive for GFAP were much less. By contrast, astrocytes were abundant in both the PLGA and PLGA-SF groups. Scale bar $=20 \mu \mathrm{m}$ in $(\mathbf{A}-\mathbf{C})$. Cells collected from the slices were lysed, and proteins were extracted for Western blotting analysis; (E) Levels of TuJ-I expression appeared higher in the PLGA-SF-NT-3 group than those in the PLGA, or PLGA-SF groups. Proteins extracted from the rat brain were used as a positive control (brain); (F) Quantification of TuJ-I blot normalized against GAPDH. ( $<<0.05 ; \mathrm{n}=3$ for each group); (G) Western blotting against GFAP; $(\mathbf{H})$ Quantitative analysis showed that the level of GFAP in the PLGA-SF-NT-3 was lower than that of any other groups $(P<0.05 ; n=3$ for each group). Stars in (D), (F), and $(\mathbf{H})$ indicate $P<0.05$ when PLGA-SF-NT-3 versus PLGA or PLGA-SF.

Abbreviations: NSCs, neural stem cells; PLGA, poly-(lactic acid-co-glycolic acid); SF, silk fibroin; NT-3, neurotrophin-3; Map2, microtubule-associated protein 2; GFAP, glial fibrillary acidic protein; DAPI, 4',6-diamidino-2-phenylindole; TuJ-I, neuron-specific class III beta-tubulin; GAPDH, Glyceraldehyde 3-phosphate dehydrogenase.

To further examine the formation of intercellular synapses among grafted cells, TEM was performed on the PLGA-cell constructs. Three PLGA slices were taken from each experimental group, and 5-6 random fields were taken in each sample under TEM. TEM showed that both neurons and glial cells had distinguishing morphological features. In general, neurons have nuclei with a lower electron density and well-demarcated nucleoli. Figure 5E shows a typical neuron extending neurites from soma, and connecting to a neurite from another cell. Under higher magnification (Figure 5F), this connection 
Table I Comparison of cell-types (mean \pm SD \%) among different groups

\begin{tabular}{lllll}
\hline Groups & n & Map2 & GFAP & O4 \\
\hline PLGA $^{\mathrm{a}}$ & 3 & $15.28 \pm 2.75$ & $76.57 \pm 3.56$ & $7.53 \pm 1.36$ \\
PLGA-SF $^{\mathrm{b}}$ & 3 & $21.37 \pm 3.89$ & $71.21 \pm 4.75$ & $6.41 \pm 2.04$ \\
PLGA-SF-NT-3 $^{\mathrm{c}}$ & 3 & $81.15 \pm 4.99$ & $11.35 \pm 4.86$ & $7.12 \pm 1.83$ \\
\hline
\end{tabular}

Notes: One-way analysis of variance was used to show the statistical difference. Map2: $P<0.05$ a versus b; a versus c; $b$ versus c; GFAP: $P<0.05$ a versus c; $b$ versus c; $P>0.05$ a versus $b$; O4: $P>0.05$ a versus $b$; a versus $c$; $b$ versus $c . a, b$, and $c$ in the table represent PLGA, PLGA-SF, and PLGA-SF-NT-3 group, respectively.

Abbreviations: Map2, microtubule-associated protein; GFAP, glial fibrillary acidic protein; PLGA, poly-(lactic acid-co-glycolic acid); SF, silk fibroin; NT-3, neurotrophin-3.

showed typical synaptic features, including specialized highdensity pre- and postsynaptic membrane, synaptic cleft, and vesicles on its terminal (arrow in Figure 5F). These results were consistent with that of double-immunohistochemistry, and suggest that synaptic formation is likely to be optimal in the presence of NT-3, which is released from both NT-3loaded PLGA scaffold and SCs.

\section{Synaptic activity of differentiated NSCs}

Due to the presence of synaptic structures in the PLGA-SFNT-3 group, we then decided to test whether these synaptic structures were functional. Cells cultured in the scaffold for 14 days were preloaded with FM1-43 or FM4-64, which stained recycling synaptic vesicles from endocytosis under depolarizing conditions $\left(50 \mathrm{mM}\left[\mathrm{K}^{+}\right]\right){ }^{21,22}$ In order to eliminate nonspecific labeling on the plasma membrane of neuronal cell body, cells in the PLGA scaffolds were rinsed extensively with PBS after the preloading process.
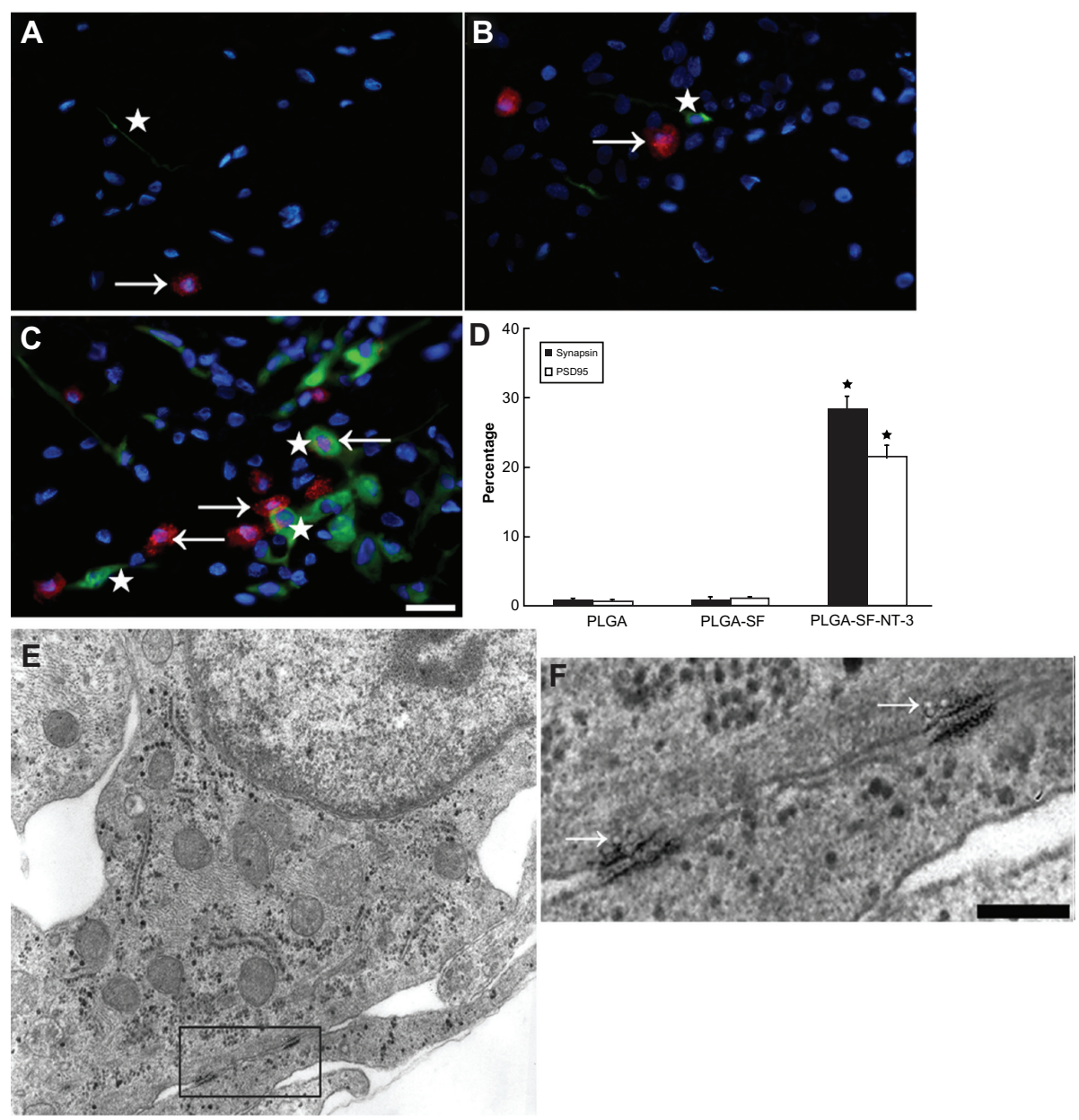

Figure 5 Synaptic formation of culture cells in the NT-3-PLGA carriers. Cells were immunostained with antibodies against pre- and postsynaptic markers (PSD95 versus synapsin). Nuclei were labeled by DAPI (blue). (A) Only a few cells expressed synapsin (stars in $\mathbf{A}-\mathbf{C}=$ green) and PSD95 (arrows in A-C = red) in the PLGA group. PSD95 was localized in the cell body; whereas synapsin was expressed in both the cell body and neurite; (B) Synapsin- or PSD95-positive cells were sparse in the PLGA-SF group; (C) In the PLGA-SF-NT3 group, the cells expressed (I) cells positive for either PSD95 or synapsin; (2) cells positive for both PSD95 and synapsin; (3) cells with positive PSD95-staining in the body, but receiving synapsin-positive neurites extending from another cell; (D) Cells with staining of PSD95 and synapsin were manually counted. Compared with other groups, positively stained cells $\left(\right.$ Synapsin ${ }^{+}$or PSD95 $\left.{ }^{+}\right)$in the PLGA-SF-NT3 group were significantly higher than any other groups $(P<0.05$; the star in D indicates $P<0.05$ when PLGA-SF-NT-3 versus PLGA or PLGA-SF); (E) Under transmission electron microscopy (TEM), a neuron was identified in PLGA-SF-NT-3 group. Note the neurite extending from the soma of one cell and connecting to a neutrite of another cell. (F) High magnification TEM of synapse formation in cultured cells, revealing specialized high-density pre- and postsynaptic membrane, synaptic cleft, and vesicles in its terminal.

Note: Scale bar $=20 \mu \mathrm{m}$ in A-C, $200 \mathrm{~nm}$ in F.

Abbreviations: NT-3, neurotrophin-3; PLGA, poly-(lactic acid-co-glycolic acid); PSD95, postsynaptic density-95; DAPI, 4',6-diamidino-2-phenylindole; SF, silk fibroin. 
A second depolarization was then induced by raising the $\mathrm{K}^{+}$concentration, which led to the release of FM1-43 or FM4-64 by exocytosis (Figure 6). At the beginning of $\mathrm{K}^{+}$stimulation, plenty of fluorescent puncta (FM1-43 or FM4-64) appeared in the neurites, particularly at the sites where neurites crossed over each other in the PLGA-SFNT-3 group (see arrow in Figure 6A and E). By contrast, barely detectable fluorescent puncta appeared in the PLGA-only group after preloading (Figure 6C), suggesting dramatically reduced endocytosis of puncta in this group. When cells were subjected to continuous stimulation for 3 minutes, fluorescent puncta disappeared or reduced in intensity in many neurites in the PLGA-SF-NT-3 group (see arrows in Figure 6B, and F). However, in the PLGA-only group, fluorescence intensity and distribution remained unchanged (Figure 6D).

To quantitatively track the changes of fluorescence intensity, we next used fluorescence microscopy to continuously record preloaded cells for 5 minutes in the PLGA-SFNT-3 group. A decline in FM1-43 intensity was observed in several waves during this process (Figure 6G). These results suggest that synaptic vesicles in our cultured neurons are able to fuse with the plasma membrane, with their contents diffusing into the pericellular compartment. ${ }^{21,22}$ By contrast, neuronal cell bodies used as an experimental control showed no apparent change of fluorescence over time (see arrow in Figure 6G).

\section{Myelination of grafted cells}

To determine whether neurites become myelinated by coseeded SCs in the PLGA scaffolds, we performed respective double-immunostaining for Map2 and MBP, the markers for neuron and myelin sheaths. As shown in Figure 7, MBP-positive fibers (arrows in Figure 7A-C; green) costained with neurites (red) were evident in our coculture system. The percentage of MBP-positive fibers was significantly higher in the PLGA-SF-NT-3 group, compared with others $(P<0.05$; Figure 7D). This finding indicates the development of robust myelin structures in the PLGA-SF-NT-3 group. Furthermore, EM images of cultured neurons clearly reveal the presence of a myelin sheath (Figure 7E), which as seen is typically composed of several layers wrapping around axons in the PLGA-SFNT-3 group (Figure 7F).

\section{Discussion}

Repairing neuronal circuits after SCI remains a significant challenge, due to the permanent disruption of descending/ ascending pathways caused by host cell death and tissue disorganization, including demyelination. Although resident endogenous NSCs exist on the central canal lining of the adult spinal cord, ${ }^{23}$ their recruitment is limited in response to injury. ${ }^{24}$ Exogenous NSCs transplantation was proposed to be a strategy for spinal cord regeneration. ${ }^{3,12,21}$ However, whether these grafted cells are able to survive, differentiate
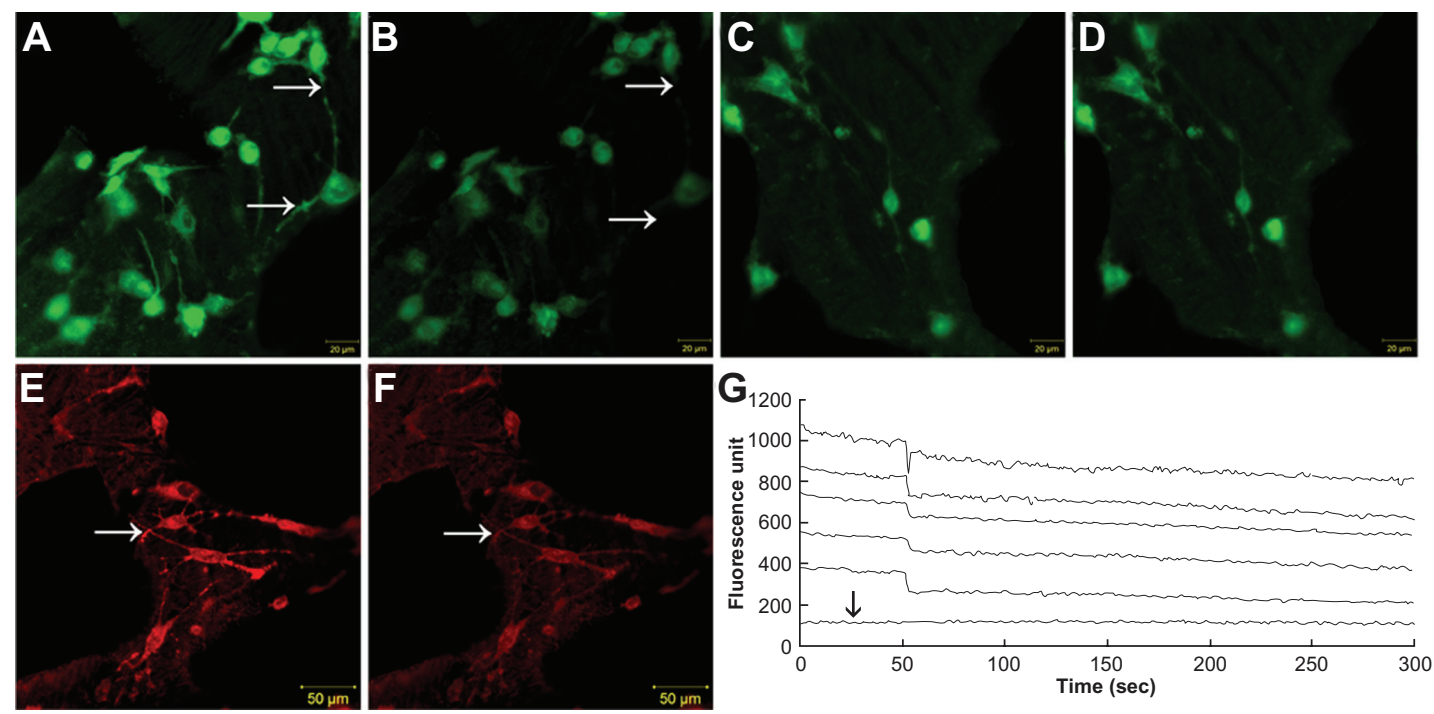

Figure 6 Release of synaptic vesicles during depolarization by high [ $\left.\mathrm{K}^{+}\right]$. (A) In the PLGA-SF-NT-3 group, FMI-43 fluorescent puncta were particularly concentrated at sites where neurites crossed over (see arrows) under stimulation of high $\left[\mathrm{K}^{+}\right](50 \mathrm{mM})$; (B) After 3-minute stimulation by the high [ $\left.\mathrm{K}^{+}\right]$, fluorescence intensity of these puncta was weakened or disappeared; (C) By contrast, uptake of the fluorescent signal into the cells in the NSCs group was only minimal, and showed weak fluorescence prior to three-minute stimulation; (D) Fluorescence intensity remained unchanged after the stimulation period; (E) FM4-64 fluorescent puncta before; and (F) after stimulation of high $\left[\mathrm{K}^{+}\right] ;(\mathbf{G})$. FMI-43 fluorescence was tracked on the cells in the PLGA-SF-NT-3 group, which was continuously depolarized for 5 minutes. Recording from the cytoplasm was used as a control, and showed no significant change over the 5-minute period (arrow in $\mathbf{G}$ ).

Abbreviations: PLGA, poly-(lactic acid-co-glycolic acid); SF, silk fibroin; NT-3, neurotrophin-3; NSCs, neural stem cells; FMI-43, [(N-3-triethylammonmpropyl)-4(4-(dibutylamino)styryl)]; FM4-64, [N-(3-triethylammoniumpropyl)-4-(6-(4-(diethylamino)phenyl) hexatrienyl)pyridiniumdibromide]. 

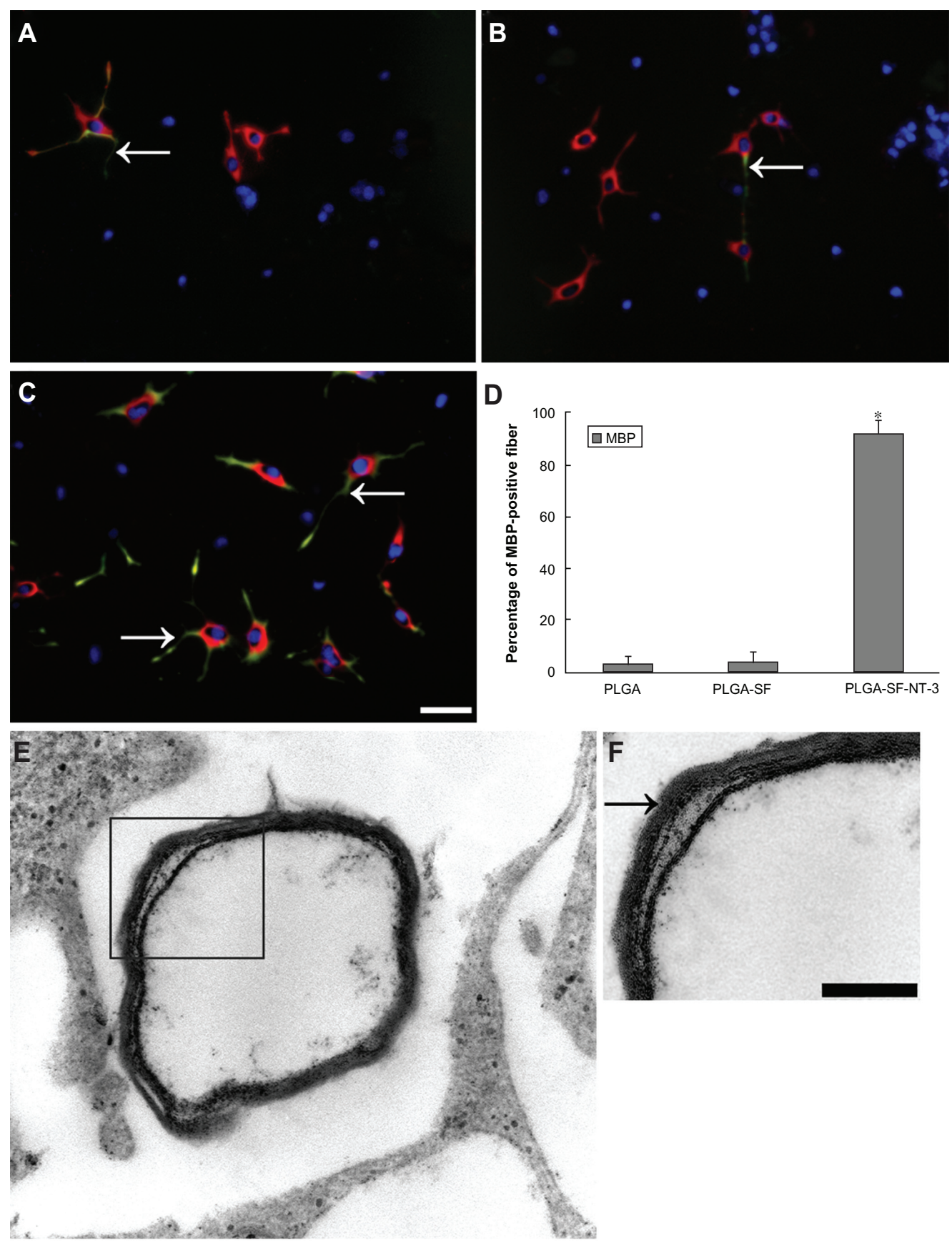

Figure 7 Formation of myelin sheath in the coculture system. NSCs and SCs in the cells/PLGA were cultured for 14 days, and immunostained with antibodies against neuron and myelin sheath markers (Map2 = red versus MBP = green). Nuclei were labeled by DAPI (blue). (A) Arrow indicates segments of neuronal axons wrapped by (MBPpositive) myelin sheath in PLGA; (B) the PLGA-SF group; and (C) PLGA-SF-NT-3 group, respectively; (D) Abundance of MBP-positive fibers in the PLGA-SF-NT-3 group compared with other groups ( $P<0.05 ; n=3$ for each group); (E) TEM showing formation of the myelin sheath in the PLGA-SF-NT-3 group; (F) Typical, characteristic sheath composed of several layers wrapped around axons.

Note: Scale bar $=20 \mu \mathrm{m}$ in (A-C), $200 \mathrm{~nm}$ in (F).

Abbreviations: NSCs, neural stem cells; SCs, Schwann cells; PLGA, poly-(lactic acid-co-glycolic acid); SF, silk fibroin; NT-3, neurotrophin-3; Map2, microtubule-associated protein 2; MBP, myelin basic protein; TEM, transmission electron microscopy.

into neurons, form myelin structures, and then re-establish a functioning neuronal network, remains unknown.

In this study, we cocultured NSCs and SCs in NT-3-loaded PLGA carriers, and systemically investigated the survival and differentiation of cultured cells in relation to the nature of the scaffold matrix. Recent approaches employed for neuronal culture have aimed at embedding or encapsulating neurotrophic factors into a polymer ${ }^{13,20,21}$ or protein matrix ${ }^{25}$ to treat SCI. SF has already exhibited excellent biocompatibility both in vitro ${ }^{25,26}$ and in vivo, ${ }^{27}$ good mechanical properties, ${ }^{28}$ and a slow rate of biodegradation. Embedding NTs into SF is considered a viable strategy for 
long-term NT release. ${ }^{25}$ Our study exhibited excellent release of NT-3 from NT-3-loaded PLGA carriers. We found that NT-3 release persists for longer than 4 weeks. This is consistent with recent studies reporting that bioactive NT-3 can be detected from 1 hour to 4 weeks due to its embedding into chitosan carriers. ${ }^{13,20}$ Our experiment not only demonstrates a stable and constant rate of NT-3 release, it also provides a suitable concentration of SF solution for the embedding of neurotrophic factors.

Different NT-3 release profiles were observed when equal amounts of NT-3 were embedded into three different concentrations of SF solution. This may be due to the strong interaction between NT-3 and SF, owing to the opposite charge of two proteins. The fact that cumulative NT-3 release is highest in the case of the $3 \%$ SF solution may be due to the stronger interaction between NT and SF in the $6 \% \mathrm{SF}$ solution, whereas in the $1 \%$ SF solution, much less NT was sequestered in the first place. Thanks to the constant release of NT, our data showed excellent survival of grafted cells (dead cells were $<4 \%$ ), and demonstrated a uniform survival rate in both the peripheral and central sections of the slices from the three scaffold types. Taken together, these findings suggest a promising NT-3 delivery system, which will benefit both neural survival and the differentiation of grafted cells.

Our data clearly showed that the majority of NSCs differentiated into neurons in NT-3-loaded PLGA carriers. More importantly, these neurons also exhibited synaptic plasticity, formed synapses and myelin sheaths with SCs, and established a functional neural construction in vitro. This premise is supported by several lines of evidence. (1) morphology of synaptic structures and myelination was observed by the use of TEM and double-immunostaining; (2) the synaptic structures were excitable when subjected to external stimuli (ie, a high $\mathrm{K}^{+}$concentration). We found that synaptic vesicles tracked by fluorescence dye (FM1-43 or FM4-64) were released upon depolarization.

Neuronal differentiation is a prerequisite for constructing a neural network in vitro. In our study, NSCs showed different degrees of differentiation in the three coculture conditions. In the PLGA-SF-NT-3 group, the percentage of Map2-positive cells was higher than in the other groups ( $81.15 \%$ versus $15.28 \%$ and $21.37 \%$, respectively). On the contrary, the percentage of GFAP-positive cells was lower. These findings are further supported by the blot detection of TuJ-1 and GFAP. Similar results have also been reported in others' earlier works. ${ }^{13,20}$

Furthermore, it is well-known that extracellular matrix (ECM) components play a role in the differentiation of
NSCs into neurons. ${ }^{29,30}$ Our data showed that the rate of Map2-positive cells was higher in the PLGA-SF group than in the PLGA-only group. These results not only demonstrated the known function of NT-3 in neuronal survival and differentiation, but also suggested that SF may contribute to the differentiation of neurons.

The presence of double-immunostaining on cultured cells showed a robust signal against synaptic markers, synapsin and PSD95. Percentages of either synapsin- or PSD95positive cells were highest in the PLGA-SF-NT-3 group. This suggests that abundant synaptic connections are formed inside PLGA scaffolds, which is also consistent with the role of NTs in synaptic formation. ${ }^{18}$ Furthermore, electron microscopy studies showed the presence of mature synapses, including specialized, high-density pre- and postsynaptic membrane, synaptic cleft, and vesicles in its terminal.

To test whether these synaptic connections are functional, we used two different fluorescent dyes, FM1-43 and FM4-64, to specifically label synaptic vesicles under high $\mathrm{K}^{+}$ depolarization conditions, ${ }^{31,32}$ and followed the fluorescent intensity of neuritis during a second depolarization. We observed that the fluorescent intensity of FM1-43-labeled neuritis during exocytosis gradually decreased, and fluorescent puncta disappeared at sites where neurites crossed over. Similar observations were also made by FM4-64 labeling. By contrast, the rate of FM1-43 fluorescent puncta uptake into NSCs was only minimal, and its intensity did not change during depolarization. Taken all together, these results suggest that the coseeding of NSCs and SCs into NT-3-loaded PLGA carriers produces abundant synaptic connections, and these synaptic connections show activity in response to external stimuli.

Axon myelination facilitates neuronal performance by increasing the speed of neuronal conductance. Some studies also support the key role of remyelination in promoting neuronal survival after injury to adult CNS. ${ }^{33}$ In the present study, abundant myelin sheaths were identified by double-immunostaining in the PLGA-SF-NT-3 group, but not in the control groups. Furthermore, the formation of myelin structure was also supported by EM analysis, which revealed robust myelinated axons in the PLGA-SFNT-3 group.

\section{Conclusion}

In the present study, we successfully constructed a protein delivery system in vitro, which releases bioactive NT-3 stably and constantly. Coseeding NSCs and SCs into these NT-3-loaded PLGA carriers not only permitted survival of grafted cells, but also promoted the differentiation 
of NSCs into neurons. These neurons developed synaptic connections, exhibited synaptic activities, and became myelinated by coseeded SCs on their neurites. These findings provide functional neural constructs to serve as potential conduits in neural repair. Our ongoing study will now focus on the evaluation of new construction in an in vivo model of SCI, to promote the recovery of both motor and sensory functions.

\section{Acknowledgments}

We thank the Chinese National Natural Science Foundation (30900774 to Y Xiong; 81000465 to J Wan; U1134007, 20974128 and 51073178 to DP Quan), Shenzhen-Hong Kong Innovation Foundation (08fz-08) and the China Postdoctoral Science Foundation (20090460788) for financial support. We also thank Shenzhen Biomedical Research Support Platform for the technical help. We thank Dr Kepeng Wang for revising our manuscript.

\section{Disclosure}

The authors declare no conflicts of interest in this work.

\section{References}

1. Faden AI. Experimental neurobiology of central nervous system trauma. Crit Rev Neurobiol. 1993;7(3-4):175-186.

2. Fawcett JW, Asher RA. The glial scar and central nervous system repair. Brain Res Bull. 1999;49(6):377-391.

3. Olson HE, Rooney GE, Gross L, et al. Neural stem cell- and Schwann cell-loaded biodegradable polymer scaffolds support axonal regeneration in the transected spinal cord. Tissue Eng Part A. 2009;15(7):1797-1805.

4. Bunge RP. The role of the Schwann cell in trophic support and regeneration. J Neurol. 1994;242(1 Supp1 1):S19-S21.

5. Oka N, Kawasaki T, Matsui M, Tachibana H, Sugita M, Akiguchi I. Neuregulin is associated with nerve regeneration in axonal neuropathies. Neuroreport. 2000;11(17):3673-3676.

6. Hurtado A, Moon LD, Maquet V, Blits B, Jerome R, Oudega M. Poly (D,L-lactic acid) macroporous guidance scaffolds seeded with Schwann cells genetically modified to secrete a bi-functional neurotrophin implanted in the completely transected adult rat thoracic spinal cord. Biomaterials. 2006;27(3):430-442.

7. Chen BK, Knight AM, de Ruiter GC, et al. Axon regeneration through scaffold into distal spinal cord after transection. J Neurotrauma. 2009; 26(10):1759-1771.

8. Oudega M, Gautier SE, Chapon P, et al. Axonal regeneration into Schwann cell grafts within resorbable poly(alpha-hydroxyacid) guidance channels in the adult rat spinal cord. Biomaterials. 2001;22(10): $1125-1136$.

9. Temple S. The development of neural stem cells. Nature. 2001;414(6859): $112-117$.

10. Gage FH. Mammalian neural stem cells. Science. 2000;287(5457): 1433-1438.

11. Zahir T, Nomura H, Guo XD, et al. Bioengineering neural stem/ progenitor cell-coated tubes for spinal cord injury repair. Cell Transplant. 2008;17(3):245-254.

12. Zhang X, Zeng Y, Zhang W, Wang J, Wu J, Li J. Co-transplantation of neural stem cells and NT-3-overexpressing Schwann cells in transected spinal cord. J Neurotrauma. 2007;124(12):1863-1877.
13. Li X, Yang Z, Zhang A. The effect of neurotrophin-3/chitosan carriers on the proliferation and differentiation of neural stem cells. Biomaterials. 2009;30(28):4978-4985.

14. Novikova LN, Novikov LN, Kellerth JO. Differential effects of neurotrophins on neuronal survival and axonal regeneration after spinal cord injury in adult rats. J Comp Neurol. 2002;452(3):255-263.

15. Sayer FT, Oudega M, Hagg T. Neurotrophins reduce degeneration of injured ascending sensory and corticospinal motor axons in adult rat spinal cord. Exper Neurol. 2002;175(1):282-296.

16. Bible E, Chau DY, Alexander MR, Price J, Shakesheff KM, Modo M. The support of neural stem cells transplanted into stroke-induced brain cavities by PLGA particles. Biomaterials. 2009;30(16):2985-2994.

17. O'Keeffe FE, Scott SA, Tyers P, et al. Induction of A9 dopaminergic neurons from neural stem cells improves motor function in an animal model of Parkinson's disease. Brain. 2008;131(Pt 3):630-641.

18. Chao MV. Neurotrophins and their receptors: a convergence point for many signalling pathways. Nat Rev Neurosci. 2003;4(4):299-309.

19. Park KI, Himes BT, Stieg PE, Tessler A, Fischer I, Snyder EY. Neural stem cells may be uniquely suited for combined gene therapy and cell replacement: evidence from engraftment of Neurotrophin-3expressing stem cells in hypoxic-ischemic brain injury. Exp Neurol. 2006;199(1):179-190.

20. Yang Z, Duan H, Mo L, Qiao H, Li X. The effect of the dosage of NT-3/ chitosan carriers on the proliferation and differentiation of neural stem cells. Biomaterials. 2010;31(18):4846-4854.

21. Guo JS, Zeng YS, Li HB, et al. Cotransplant of neural stem cells and NT-3 gene modified Schwann cells promote the recovery of transected spinal cord injury. Spinal Cord. 2007;45(1):15-24.

22. Li Z, Burrone J, Tyler WJ, Hartman KN, Albeanu DF, Murthy VN. Synaptic vesicle recycling studied in transgenic mice expressing synaptopHluorin. Proc Natl Acad Sci U S A. 2005;102(17):6131-6136.

23. Martens DJ, Seaberg RM, van der Kooy D. In vivo infusions of exogenous growth factors into the fourth ventricle of the adult mouse brain increase the proliferation of neural progenitors around the fourth ventricle and the central canal of the spinal cord. Eur J Neurosci. 2002; 16(6):1045-1057.

24. Mothe AJ, Tator CH. Proliferation, migration, and differentiation of endogenous ependymal region stem/progenitor cells following minimal spinal cord injury in the adult rat. Neuroscience. 2005;131(1):177-187.

25. Uebersax L, Mattotti M, Papaloizos M, Merkle HP, Gander B, Meinel L. Silk fibroin matrices for the controlled release of nerve growth factor (NGF). Biomaterials. 2007;28(30):4449-4460.

26. Wenk E, Meinel AJ, Wildy S, Merkle HP, Meinel L. Microporous silk fibroin scaffolds embedding PLGA microparticles for controlled growth factor delivery in tissue engineering. Biomaterials. 2009;30(13):2571-2581.

27. Bessa PC, Balmayor ER, Hartinger J, et al. Silk fibroin microparticles as carriers for delivery of human recombinant bone morphogenetic protein-2: in vitro and in vivo bioactivity. Tissue Eng Part C Methods. 2010;16(5):937-945.

28. Liu Y, Shao Z, Vollrath F. Relationships between supercontraction and mechanical properties of spider silk. Nat Mater. 2005;4(12):901-905.

29. Nakajima M, Ishimuro T, Kato K, et al. Combinatorial protein display for the cell-based screening of biomaterials that direct neural stem cell differentiation. Biomaterials. 2007;128(6):1048-1060.

30. Stabenfeldt SE, Munglani G, Garcia AJ, LaPlaca MC. Biomimetic microenvironment modulates neural stem cell survival, migration, and differentiation. Tissue Eng Part A. 2010;16(12):3747-3758.

31. Amaral E, Guatimosim S, Guatimosim C. Using the fluorescent styryl dye FM1-43 to visualize synaptic vesicles exocytosis and endocytosis in motor nerve terminals. Methods Mol Biol. 2011;689:137-148.

32. Dason JS, Smith AJ, Marin L, Charlton MP. Vesicular sterols are essential for synaptic vesicle cycling. J Neurosci. 2010;30(47):15856-15865.

33. Miron VE, Zehntner SP, Kuhlmann T, et al. Statin therapy inhibits remyelination in the central nervous system. Am J Pathol. 2009;174(5): 1880-1890. 


\section{Supplementary figure}
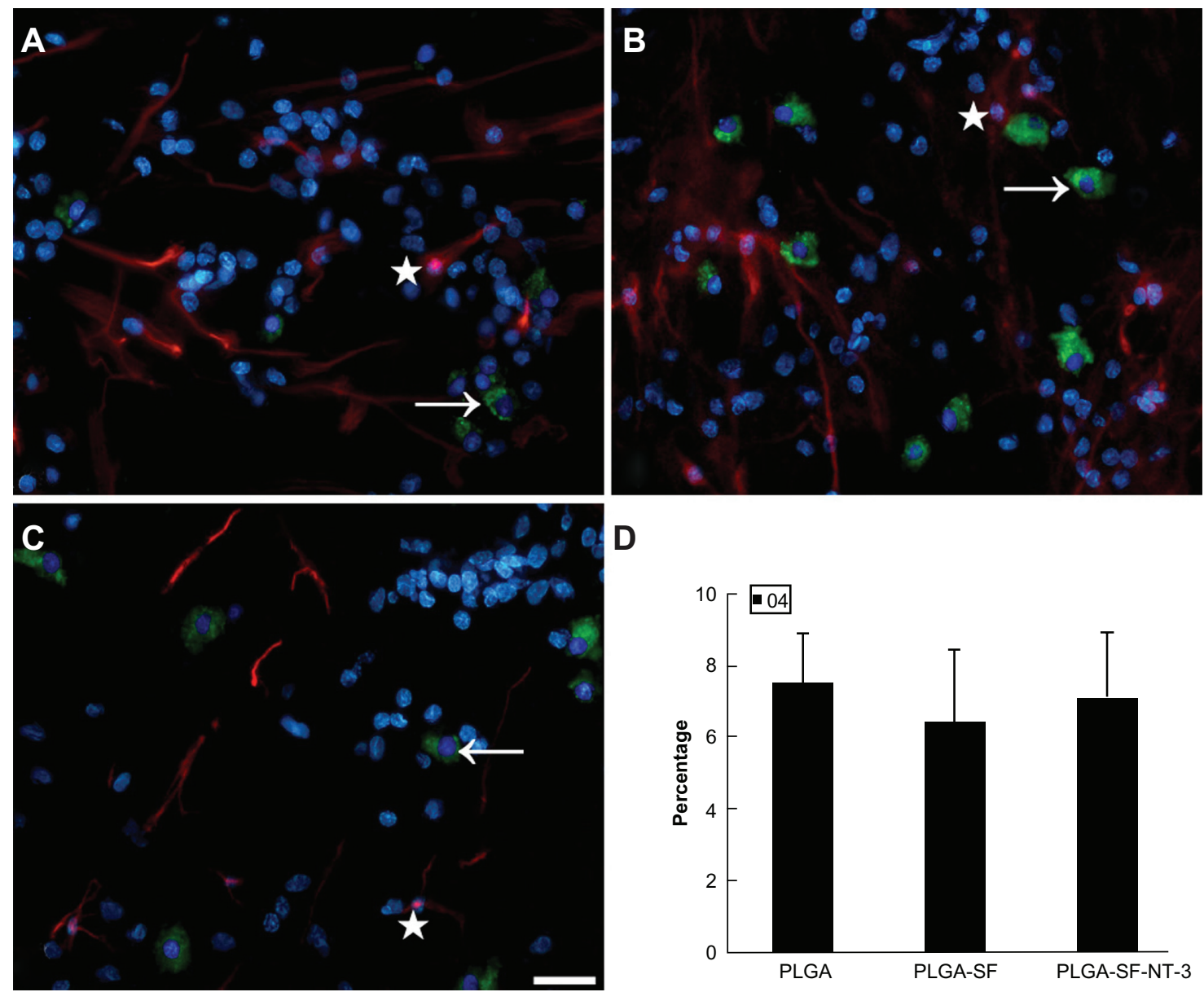

Figure SI NSCs and SCs were cultured in the scaffold for 14 days. Cells were immunostained in (A) PLGA only; (B) PLGA-SF; (C) PLGA-SF-NT-3 group with markers for astrocytes (GFAP; star; red), and oligodendrocytes (O4; arrow; green). Nuclei were stained by DAPI (blue); (D) Cells with staining of O4 were manually counted. There was no statistical difference among groups $(P>0.05 ; \mathrm{n}=3$ for each group).

Note: Scale bar $=20 \mu \mathrm{m}$ in A-C.

Abbreviations: NSCs, neural stem cells; SCs, Schwann cells; PLGA, poly-(lactic acid-co-glycolic acid); SF, silk fibroin; NT-3, neurotrophin-3; GFAP, glial fibrillary acidic protein; DAPI, 4',6-diamidino-2-phenylindole.

\section{Publish your work in this journal}

The International Journal of Nanomedicine is an international, peerreviewed journal focusing on the application of nanotechnology in diagnostics, therapeutics, and drug delivery systems throughou the biomedical field. This journal is indexed on PubMed Central, MedLine, CAS, SciSearch ${ }^{\circledR}$, Current Contents ${ }^{\circledR} /$ Clinical Medicine,
Journal Citation Reports/Science Edition, EMBase, Scopus and the Elsevier Bibliographic databases. The manuscript management system is completely online and includes a very quick and fair peer-review system, which is all easy to use. Visit http://www.dovepress.com/ testimonials.php to read real quotes from published authors.

\footnotetext{
Submit your manuscript here: http://www.dovepress.com/international-journal-of-nanomedicine-journal
} 